\title{
Review and a validation project on delayed Ettringite degradation during mass concreting
}

\author{
K S Ang, Z H Chew, S C Fan*
}

\begin{abstract}
In civil engineering construction, mass concreting of a thick foundation slab is not uncommon. The non-stop operation could lead to elevated temperature above $90^{\circ} \mathrm{C}$. It is derived from the exothermic chemical reaction. The elevated temperature favors the delayed Ettringite crystal formation, which would generate micro-cracks and hence deteriorate the strength of concrete. This paper presents a review and a project to validate the delayed Ettringite degradation through a simulated laboratory environment.
\end{abstract}

Keywords-Ettringite, mass concreting, strength degradation

\section{Introduction}

As early as in the mid-1990s, the premature deterioration of concrete pre-cast members and pavements has become well known around the Civil Engineering world in a bad manner due to the unknown reasons as to what causes their distress. Considerable amount of debate and controversy have arisen in the research and engineering practicing community in attempts of providing an explanation to the unfavorable and complex nature of these cases. The main focus is being placed on the formation and effect of a compound known as Ettringite.

In modern civil engineering construction, mass concreting of a thick foundation slab for a tall building is not uncommon. The non-stop operation could lead to elevated temperature above $90^{\circ} \mathrm{C}$ if no precautious measures are taken. It is derived from the exothermic chemical reaction of cementitious binder and water. The elevated temperature favors the delayed Ettringite crystal formation, which would generate microcracks and hence cause the delayed degradation of strength.

This paper presents a literature review on the Ettringite, which still appears to be unfamiliar or to some extent mysterious, to the civil engineering community. A project has set up to validate the delayed Ettringite degradation through a simulated laboratory environment to an actual construction site condition, where a thick slab of up to 10 meters was cast.

\section{Literature Review}

For over 50 years, there have been controversy [1] over whether Ettringite is formed by through-solution mechanism or by topo-chemical means has resulted in two hypotheses concerning the morphology of Ettringite in the hardened cement-paste matrix.

K S Ang, Z H Chew, S C Fan*

School of Civil \& Environmental Engineering

Nanyang Technological University, Singapore
Mehta [2] noted that Ettringite has two types of morphology, depending upon the conditions under which it forms:

Type 1: Form as long lath-like crystals with length ranging from $10-100 \mu \mathrm{m}$ and thickness several $\mu \mathrm{m}$. Formation of these crystals occurs in solution under conditions of low hydroxyl ion concentration. These crystals are also not expansive.

Type 2: Crystals are in the form of small rods with length ranging from $1-2 \mu \mathrm{m}$ and thickness $0.1-0.2 \mu \mathrm{m}$. Formation of these crystals occurs when hydroxyl ion concentration is high. Ettringite formed with this structure can be a source of weaker strength, particularly when in a confined space. Accumulation of these crystals can absorb water and expand.

Type-1 morphology will only appear when sufficient space is available such as in high water cement pastes, during early hydration or in large cavities. As for Type-2 Ettringite, the crystals will occur as "short prismatic crystals" in more confined spaces. The crystal is able to form anywhere and everywhere in the system. In addition, the lime present in Portland cement prevents the Type-2 Ettringite from forming long lath-like crystals.

Cohen [3] has categorized the hypotheses into two schools; crystal growth and swelling.

In the crystal growth school, the formation of Ettringite at the surface of reactant grains creates an inner layer which pushes the other particles out which causes the expansion. In addition, the presence of calcium hydroxide $(\mathrm{CH})$ determines the mode of formation. If $\mathrm{CH}$ is not present, the crystal growth is topochemical and Ettringite is formed from solution which does not produce expansion. Metha [2] has also shown that monosulphate formation in a confined space are less likely to result in expansion due to the plate-like monosulphate crystals being able to orient themselves like "leaves of a book". However, Ettringite crystals are not able to re-orient and resulting in expansion.

However, a number of researchers beg to differ on the hypothesis that pressure can be exerted from individual crystals. Dron et al. [4] noted that Ettringite's expansive forces can only be developed in confined space and that an uniaxial force of only $1 \mathrm{MPa}$ is capable to restrain any expansion in that direction. The location at which the matrix is formed, determines the degree of destructiveness of Ettringite. If it is formed near an aggregate particle then the destruction will be the maximum and if it is formed near a cavity then the cavity can act as an expansion chamber to contain the potential stress build-up.

Recently, Ping and Beaudoin [5, 6] claimed that the formation of Ettringite is by two processes known as crystal 
growth and nucleation. Only when crystals grow in confined space, "crystallization pressures" will be produced. This proves why the lack of confined space during the early stages of hydration does not result in Ettringite growth exerting pressure. Most of the Ettringite may form before expansion occurs but it is only the formation in confined space that caused expansion. Ping and Beaudoin $[5,6]$ note that any solid products will produce crystallization pressure if crystal growth is in confined space and the solubility product ratio is greater than 1.0 which in other words means the products are less soluble than the reactants.

In the swelling school, it basically means the Ettringite is formed by a through-solution mechanism. In a saturated $\mathrm{CH}$ environment, the Ettringite crystals are gel-like and colloidal in size. The high surface area results in absorption of significant quantities of water and thus causes strong swelling pressures to be developed.

Temperature has also played a crucial factor in the size of Ettringite being formed. When curing at $25^{\circ} \mathrm{C}$, Ettringite is detectable by X-ray analysis after a few hours [7]. When hydration occurs at $60^{\circ} \mathrm{C}$, Ettringite $\mathrm{X}$-ray peaks begin to form at 15 minutes and there is quite an amount of Ettringite after 6 hours. Therefore, it can be said that Ettringite crystals are considerably larger when formed at higher temperature than those formed at $25^{\circ} \mathrm{C}$.

In 1980, Ghorab et al. [8] performs expansion tests on mortar manufactured with typical German high-early-strength cement (with $4 \% \mathrm{SO}_{3}$ ) and sulphate resistance cement. The heat-curing temperature varied from 60 to $100^{\circ} \mathrm{C}$ within duration of 12 to 72 hours. Continuous expansion tests were performed and strains were measured for 300 days. The samples were mortar bars, 40 x 40 x $160 \mathrm{~mm}$ bars created from water cement ratio of 0.5 and cement and sand ratio of 0.33 .

The experiments indicated no major occurrence of late expansions for curing temperatures less than $80^{\circ} \mathrm{C}$ regardless of the duration of heating. For curing temperatures above $80^{\circ} \mathrm{C}$, expansions were noticed when soaking in water for 70 to 80 days. Expansion was usually ceased after 130 days. However, the mortar specimen which was being cured at $90^{\circ} \mathrm{C}$ for 18 hours, experienced continuous increasing expansion over a period of 70 to 300 days.

In a second series of experiments, specimens were subjected to a 1-day delay period followed by 1.5 days at $80^{\circ} \mathrm{C}$ and then a 6-hour temperature rise to $100^{\circ} \mathrm{C}$; immediate cooling then followed, causing the specimens to reach maximum temperature. Fig. 1 shows the expansion of bars which were manufactured based on different blends of sulphate-resistant (SR) and high-early-strength (HES) cements. Blends which contained more than $25 \%$ high-earlystrength cement have shown substantial expansions which starts after soaking in water for 70 days.

In a third series of experiments, Ghorab et al. [8] examined the effect of pozzolans on the expansion mechanism. Various cement/pozzolan blends were used to prepare the mortar specimens. Followed by conducting the above-mentioned tests on the specimens, it was found that the pozzolan has substantially reduced expansions.

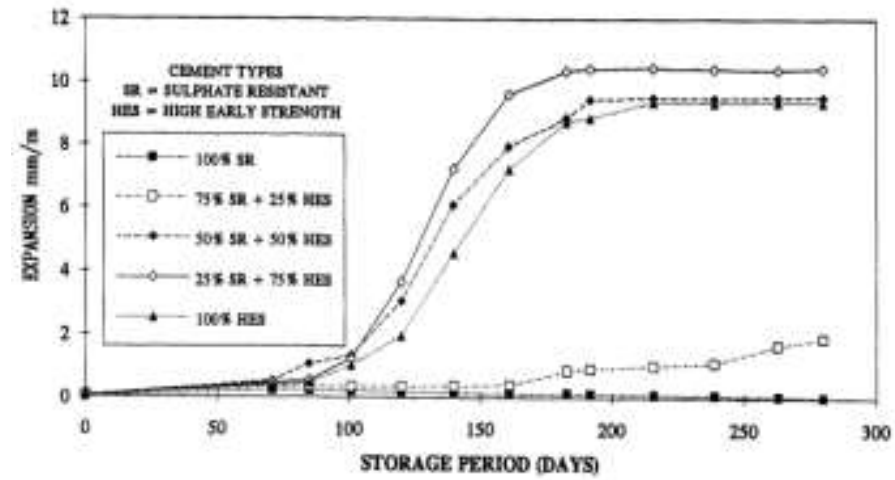

Figure 1: Examples of Various Mortars after Heat Treatment (Ghorab et al. [8])

Based on the results of his experiments, Ghorab et al. [8] suggests that the expansions are due to the formation of stable Ettringite with time, derived from the monosulphate and solid solutions which contains tetracalcium aluminate hydrate. Xray analysis clearly shows the development with time of the Ettringite X-ray peak in the heat-cured sample but not in the sample continuously cured at $20^{\circ} \mathrm{C}$. When calcium carbonate is present or carbonation is significant, Ghorab et al. [8] proposes that these can increase the damage caused by the gradual transformation to Ettringite.

In 1988, Sylla [9] noticed that as the temperature increases in concrete, both the reactivity and speed of dissolution of tricalcium aluminate $\left(\mathrm{C}_{3} \mathrm{~A}\right)$ increases, while the available sulphate in solution decreases concurrently. This causes an increased tendency to form monosulphate rather than Ettringite. The importance of the treatment temperature and heat treatment period on the quantity of Ettringite present are shown in Fig. 2. Results are based on cement pastes made with two different types of cements. Both cements had approximately the same sulphate content but cement $\mathrm{B}$ has $12.1 \% \quad \mathrm{C}_{3} \mathrm{~A}$ while cement $\mathrm{A}$ had $8.7 \% \quad \mathrm{C}_{3} \mathrm{~A}$. The extra aluminate in cement $\mathrm{B}$ results in monosulphate forming in some pastes when treated at 60 and $80^{\circ} \mathrm{C}$. The high $\mathrm{C}_{3} \mathrm{~A}$ cement also shows a more rapid reduction in Ettringite content.

By post mortem studies of deteriorated concretes, researchers were able to collect information on how Ettringite and other crystalline materials were formed. Many past studies have shown that crystalline deposits within the capillary and air-entrained porous structure.

In a study carried out by St. John [10], he noted that Ettringite crystals are frequently found in pores and cracks of concrete which have deteriorated. The reason is due to movement of fluids through the pore structure which causes the crystals to be deposited in the voids. Also in a study carried out by Gillott and Richie [11] examined cement pastes that were 50-70 years old and observed various crystals forming in the small voids in the pastes. These crystals were identified as thin plates which frequently extend from one side of the void to the other and the radiating clusters of needles were identified as Ettringite crystals. 


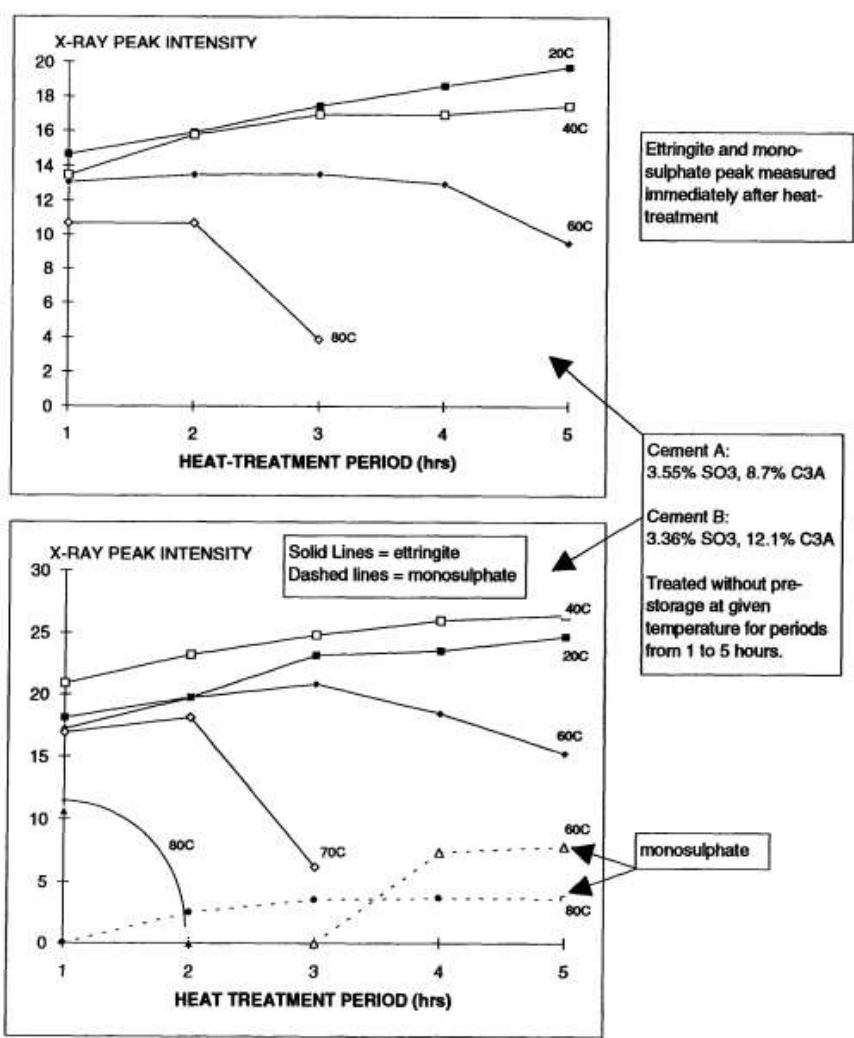

Figure 2: Variation in X-Ray Peak Intensity with Curing Temperature (Sylla [9])

\section{Validation Project}

A project was set up to carry out an investigation on the effect of elevated temperature and various chemical components existing in concrete on the formation of Ettringite. A simulated laboratory environment was set up to mirror the actual site condition during the mass concreting of the 6 9meter thick foundation slab of a tall building, where the concrete was poured continuously without stopping, resulting in elevated temperature beyond $90^{\circ} \mathrm{C}$.

Concrete cylinders samples are to be cast and compressive strength tests would be carried out. Some small crushed specimens would be taken to the material laboratory for microscopic investigation, using a Scanning Electron Microscope (SEM) and Energy Dispersive X-ray (EDX). The obtained results, in particular the presence of Ettringite formation (if any), will be compared with those obtained from the construction site.

\section{A. Preparation of Specimens}

Specimens were obtained by chipping off from cylindrical samples. Prior to loading into the electron microscope for scanning, specimens were oven-dried and reduced to a surface area of approximately $0.2 \times 0.2 \mathrm{~mm}$ and a thickness of $0.2 \mathrm{~mm}$ as shown in Fig. 3 (placed on a carbon tape). Surface of the samples were made as even as possible to avoid electron distorting. Conductive coatings were then applied on it for the electron beam to properly image as shown in Fig. 4.

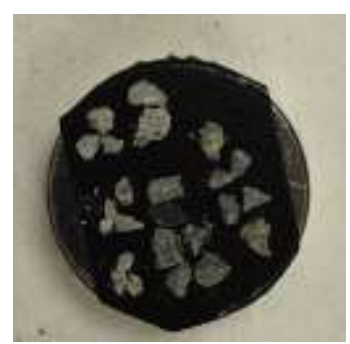

Figure 3: Specimens for Scanning

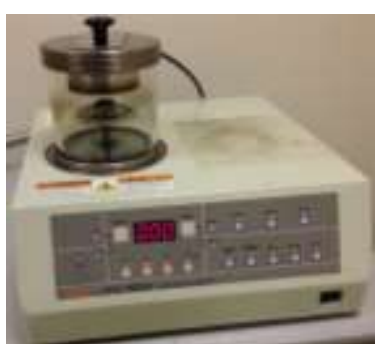

Figure 4: Apply Conductive Coating

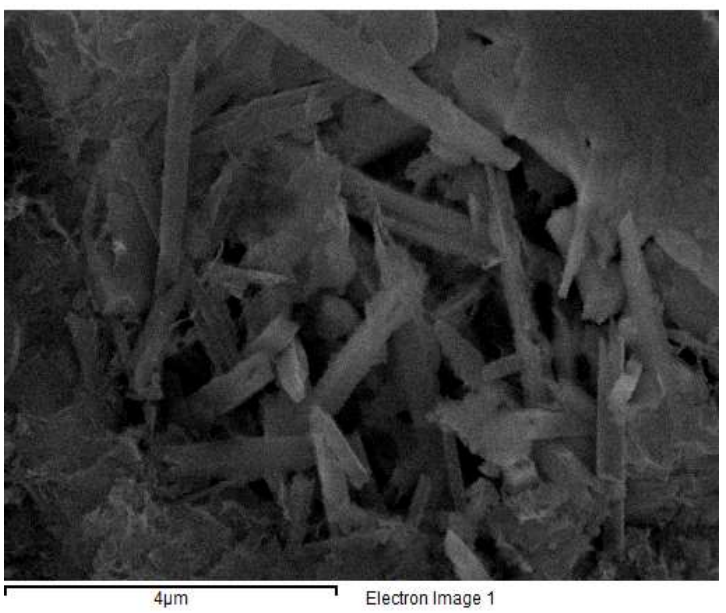

Figure 5: FESEM Image at 30,000X, Spatial Resolution of 50 to $100 \mathrm{~nm}$ of a Specimen from Core Sample (Labelled 2.1-2)

\section{B. Microscopic Analysis}

By utilizing the Field Emission Scanning Electron Microscope (FESEM), high resolution micro-structure images were observed and captured at high magnification. In it, a field-emission cathode from an electron gun provides narrow proving beams at both low and high electronenergy producing a less electrostatically distorted and sharper images with spatial resolution down to $1.5 \mathrm{~nm}$. It will make the identification of Type-1 and Type-2 Ettringite if present, possible. Fig. 5 shows an image capturing the needle-shaped Type-2 Ettringite crystal in a specimen of core sample (labelled 2.1-2)

\section{Chemical Composition Analysis}

Energy Dispersive X-ray (EDX) spectroscopy is an x-ray technique which is used to identify the chemical element composition of the specimens. Delayed Ettringite Formation (DEF), also known as Type-2 Ettringite is a chemical compound $3 \mathrm{C}_{\mathrm{a}} \mathrm{O} \cdot \mathrm{Al}_{2} \mathrm{O}_{3} \cdot 3 \mathrm{CaSO}_{4} \cdot 31 \mathrm{H}_{2} \mathrm{O}$, which is also known as high sulfate calcium sulfoaluminate. To identify the presence of DEF, the chemical elements to search for were narrowed down to the three major elements $(\mathrm{Ca}, \mathrm{Al}$ and $\mathrm{S})$. Figs. 6, 7, 8 show the images captured by EDX, which reveals the amount of elements present in the particular magnified location of specimen (same location as in Fig. 5). The white spots indicate that the respective chemical elements were present at that particular location. The total ccomposition is listed in Table 1. 


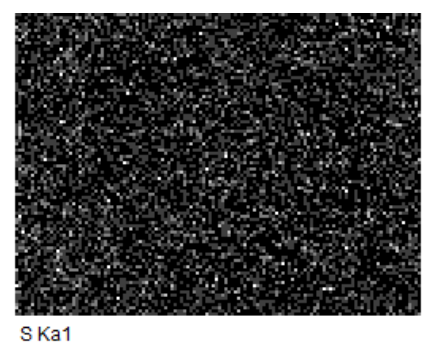

Figure 6: EDX Image for Sulfur

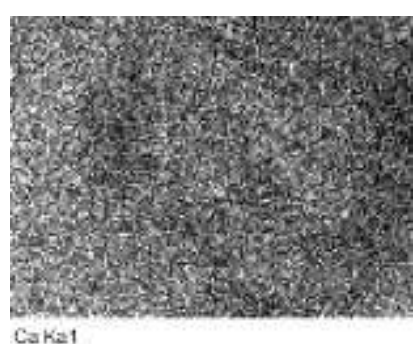

Figure 7: EDX Image for Calcium

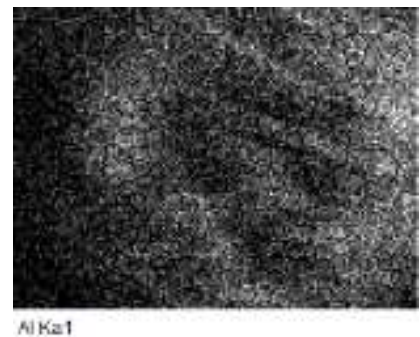

Figure 8: EDX Image for Aluminum

TABLE 1 ChEMICAL ELEMENT COMPOSITION OF SPECIMEN

\begin{tabular}{|c|c|c|}
\hline \multirow{2}{*}{ Element } & \multicolumn{2}{|c|}{ Composition \% } \\
\cline { 2 - 3 } & \% by weight & Atomic \% \\
\hline $\mathrm{C}$ & 3.20 & 5.31 \\
$\mathrm{O}$ & 57.36 & 71.46 \\
$\mathrm{Mg}$ & 1.22 & 1.00 \\
$\mathrm{Al}$ & 8.07 & 5.96 \\
$\mathrm{Si}$ & 10.04 & 7.12 \\
$\mathrm{~S}$ & 0.32 & 0.20 \\
$\mathrm{~K}$ & 0.35 & 0.18 \\
$\mathrm{Ca}$ & 16.13 & 8.02 \\
$\mathrm{Ti}$ & 0.28 & 0.12 \\
$\mathrm{Fe}$ & 1.26 & 0.45 \\
$\mathrm{Pt}$ & 1.78 & 0.18 \\
\hline Total & 100.00 & --- \\
\hline
\end{tabular}

\section{Compressive Strength Test}

Compressive strength test was carried to investigate whether there is degradation in strength in association of the presence of Ettringite formation. The sample size is $100 \mathrm{~mm}$ in diameter and $200 \mathrm{~mm}$ high as shown in Fig. 9. The moment at failure is captured in Fig. 10, and the crushed sample is shown in Fig. 11. The compressive strength of $39.6 \mathrm{~N} / \mathrm{mm}^{2}$ for a specimen from core sample (labelled 2.1-2) was registered.

\section{Iv. Remarks and Discussions}

It has been widely cited [12] that early-aged concrete subjected to temperatures higher than $70^{\circ} \mathrm{C}$ would likely, when cooled down later, lead to delayed reformation of Ettringite (which might be destroyed at early stage by the high temperature). This 'delayed ettringite formation' (DEF) is

harmful as its volumetric expansion would lead to deterioration in the hardened concrete [13]. However, the cited temperature conditions for harmful expansion of DEF is necessary but not sufficient, although laboratory data support that deleterious expansions have not been observed at $70^{\circ} \mathrm{C}$ or less, regardless of cement characteristics [14]. Besides the necessarily higher early-age temperatures above $70^{\circ} \mathrm{C}$, the sufficient conditions for DEF requires the presence of other substances, essentially ample moisture and excessive sulphate as illustrated in Fig. 12.

During masss concreting, the elevated temperature of concrete does not warrant the DEF. A simulted environment could be set up to investigate the probability of the DEF with attention drawn to the cement characteristics. The objective of this project is carry out a laboratory simulation of the mass concreting and to verify whether serious DEF is present in a similar site condtion. The methodology was presented above. The limited observations and data are far from sufficient to drawing meaningful conclusion. More specimens and samples will be investigated. The mechanical tests for compressive strength is meant to answer the question as to whether the strength is degraded with regard to the relative amount of DEF present.

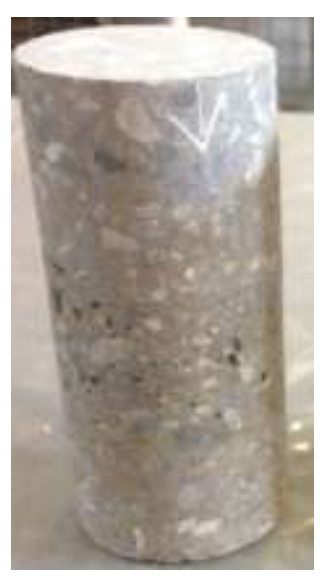

Figure 9: Cylindrical Sample

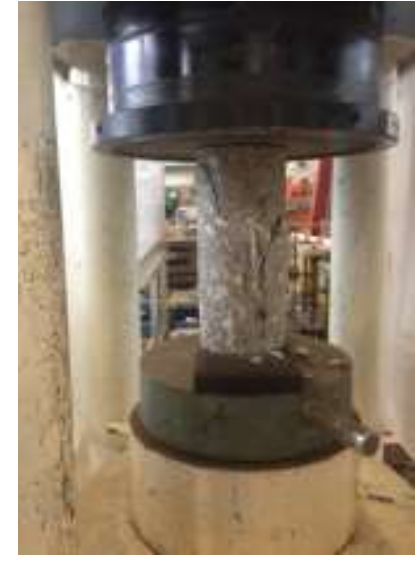

Figure 10: Compressive Test

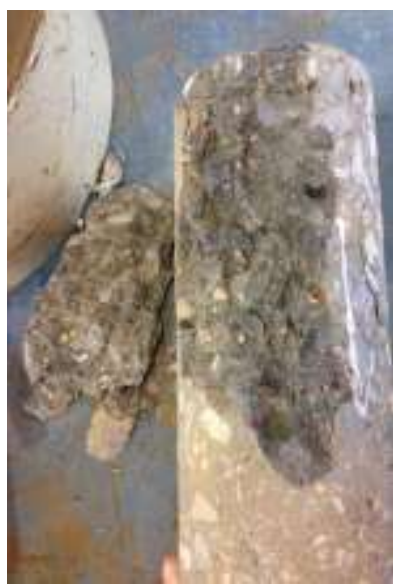

Figure 11: Crashed Sample 


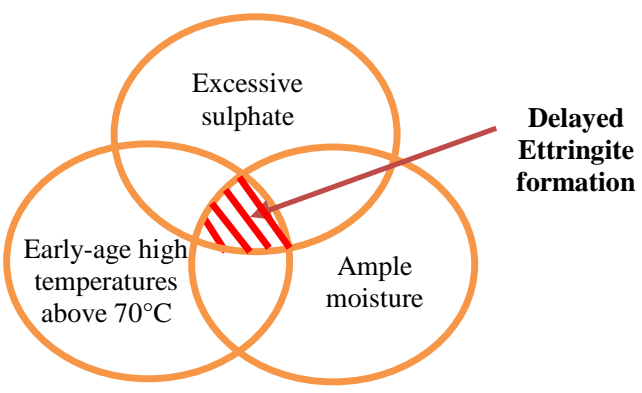

Figure 12: Essential Conditions for DEF

\section{References}

[1] M. Basista, and W. Weglewski, Micromechanical modelling of sulphate corrosion in concrete: influence of ettringite forming reaction, Theoret. Appl. Mech., vol. 35, No. 1-3, pp.29-52, 2008.

[2] P. K. Metha, Mechanism of sulfate attack on Portland cement concrete another look, Cem. Conr. Res., vol. 13, no. 3, pp.401-406, May 1983.

[3] M. D. Cohen, Modeling of expansive cement, Cem. Conr. Res., Vol. 13, pp.519-528, 1983.

[4] R. Dron, and F. Brivot, Ettringite Expansion, Bulletin de Liaison des laboratories des Ponts et Chasussees, English translation, ISSN 0458$5860,1990$.

[5] X. Ping, and J. J. Beaudoin, Mechanism of Sulphate Expansion I. Thermodynamic Principle of Crystallization Pressure, Cem. Concr. Res., vol. 22, pp.631-640, 1992.

[6] X. Ping, and J. J. Beaudoin, Mechanism of Sulphate Expansion II. Validation of Thermodynamic Theory, Cem. Concr. Res., vol. 11, pp.845-854, 1992.

[7] H. F. W. Taylor, Cement Chemistry, Academic Press, London, 1990.

[8] H. Y. Ghorab, and S. H. Abou El Fetouh, New approach to the hydration reaction of the tricalcium aluminate with gypsum at $30^{\circ} \mathrm{C}$. Part I: Effect of Lime, Zement-Kalk-Gips, vol. 38, no. 5, pp. 267-270, May 1985.

[9] H. M. Sylla, Reaktionen im Zementsteine durch Warmebehandlung (reactions in cement stone due to heat treatment), Beton, Vol. 38, pp.449-454, 1988.

[10] D. A. St John, A discussion of the paper 'Alkali Metal Sulphate - a factor common to both alkali-aggregate reaction and sulphate attack on concrete' by K. Pettifer and P.J. Nixon, Cem. Concr. Res., vol. 11, pp.799, 1981.

[11] J. E. Gillott, and T. Ritchie, A note on the occurrence of crystals of calcium hydroxide and Ettringite in voids in hardened Portland cement paste, Mag. Concr. Res., vol. 17, no. 50, pp.3-4, March 1965.

[12] H. F. W. Taylor, Delayed Ettringite Formation - Advances in Cement and Concrete, Proceedings of an Engineering Foundation Conference, American Society of Civil Engineers, pp. 122-131, July 24-29, 1994,.

[13] Robert L. Day, The Effect of Secondary Ettringite Formation on the Durability of Concrete: A Literature Analysis, RD108, Portland Cement Association, Skokie, Illinois, 1992.

[14] S. Kelham, Influence of Cement Composition on Volume Stability of Mortar: Ettringite -The Sometimes Host of Destruction, American Concrete Institute, SP-177, Farmington Hills, Michigan, pp.27-45, 1999. 